\title{
The Use of Epidermal Growth Factor Receptor Monoclonal Antibodies in Squamous Cell Carcinoma of the Head and Neck
}

\author{
Jeffery S. Russell and A. Dimitrios Colevas \\ Division of Oncology, Department of Medicine, Stanford University Medical Center, Stanford University, Stanford, \\ CA 94305, USA \\ Correspondence should be addressed to A. Dimitrios Colevas, colevas@stanford.edu
}

Received 9 April 2012; Accepted 3 September 2012

Academic Editor: Missak Haigentz

Copyright ( 2012 J. S. Russell and A. D. Colevas. This is an open access article distributed under the Creative Commons Attribution License, which permits unrestricted use, distribution, and reproduction in any medium, provided the original work is properly cited.

\begin{abstract}
Targeting of the EGF receptor (EGFR) has become a standard of care in several tumor types. In squamous cell carcinoma of the head and neck, monoclonal antibodies directed against EGFR have become a regular component of therapy for curative as well as palliative treatment strategies. These agents have anti-tumor efficacy as a single modality and have demonstrated synergistic tumor killing when combined with radiation and/or chemotherapy. While cetuximab has been the primary anti-EGFR monoclonal antibody used in the US, variant anti-EGFR monoclonal antibodies have been used in several clinical studies and shown benefit with improved toxicity profiles. Next generation anti-EGFR monoclonal antibodies may demonstrate multi-target epitope recognition, enhanced immune cell stimulation, or conjugation with radioisotopes in order to improve clinical outcomes. Identification of the specific patient subset that would optimally benefit from anti-EGFR monoclonal antibodies remains an elusive goal.
\end{abstract}

\section{Introduction}

In 2012, head and neck cancers of the oral cavity and pharynx will make up an estimated $2.5 \%$ of cancer diagnoses in the United States and for the 40,250 new cases diagnosed, there will be an estimated 7,850 deaths [1]. Worldwide, head and neck cancers are approximately $5 \%$ of all new cancer diagnoses, with a large proportion of these cases originating in developing countries [2]. Locally advanced squamous cell carcinoma of the head and neck (SCCHN) has cure rates of only $30-60 \%$, even with combined therapeutic approaches [3]. Local recurrence rates of 30-50\% and distant metastasis rates of $13-22 \%$ illustrate the need for more effective therapies $[4,5]$.

Towards this end, molecular analysis of SCCHN has found the overexpression of the epidermal growth factor receptor (EGFR) at rates of up to $90 \%$ in tumors and EGFR overexpression has been associated with a poor prognosis [6-11]. The deregulation or inappropriate activation of the EGFR family members has been shown to drive oncogenic transformation, tumor cell proliferation, and cell survival pathways in a variety of malignancies [12-14]. Ligand binding or mutations within the EGF receptor cause activation of downstream signaling pathways, such as Ras/Raf/MAPK and PI3 K/Akt [15-17].

Thus, agents that specifically target EGFR and consequently its downstream signaling pathways are appealing candidates to enhance tumor cell killing, especially in high-expressing tumors such as SCCHN. Currently, therapy for targeting EGFR can be divided between small molecule tyrosine kinase inhibitors and monoclonal antibodies. In this paper, we will address the benefits of select monoclonal antibodies as anti-EGFR therapy in SCCHN (Table 1). This paper will focus on both curative as well as palliative treatment strategies. Furthermore, we aim to discuss treatment responses that have been enhanced with anti-EGFR monoclonal antibody therapy in combination with chemotherapy and/or radiation therapy. Finally, we will discuss novel approaches under development to improve the antitumor properties of EGFR directed monoclonal antibodies. 
TABLe 1: Anti-EGFR monoclonal antibodies in clinical use.

\begin{tabular}{|c|c|c|c|c|}
\hline Antibody & Species & $\operatorname{IgG}$ & Activate ADCC* & Skin reactions \\
\hline Cetuximab & Chimeric human/mouse & IgG1 & $\mathrm{Y}$ & $\mathrm{Y}$ \\
\hline Panitumumab & Fully human & IgG2 & $\mathrm{N}$ & Mild \\
\hline Zalutumumab & Fully human & IgG1 & $\mathrm{Y}$ & $\mathrm{Y}$ \\
\hline Nimotuzumab & Humanized & IgG1 & $\mathrm{Y}$ & $\mathrm{N}$ \\
\hline Matuzumab & Humanized & IgG1 & Y & Mild \\
\hline
\end{tabular}

*ADCC: antibody-dependent cellular cytotoxicity.

\section{Early Development of Anti-EGFR Monoclonal Antibodies}

Cetuximab (Erbitux; formerly IMC-C225) was the first monoclonal antibody used clinically to target the EGF receptor. It is a chimeric IgG1 antibody derived from both mouse and human immunoglobulin genes [40]. Cetuximab is specific for the EGFR/Her1receptor, does not cross-react with other Her receptor family members, and targets the extracellular EGFR domain $[41,42]$. Cetuximab binds with a higher affinity than the native EGF ligand to modulate ligand-mediated dimerization and activation of the receptor [43]. In addition to blocking downstream EGFR signaling pathways crucial for tumor survival, cetuximab also stimulates antibody-dependent cellular cytotoxicity (ADCC) by recruiting activated immune cells into tumors to augment tumor cell killing [44-46].

Original work by Masui et al. demonstrated that antiEGFR monoclonal antibodies were able to inhibit the growth of human tumor xenografts in nude mice when given at the time of tumor implantation [47]. In vitro, the antibodies demonstrated a primarily cytostatic effect against tumor cell lines, while in vivo, treatments with antiEGFR antibodies were unable to prevent the growth of established tumors in xenograft models $[41,47]$. Limitations in the in vivo setting may have been an inability of the antibody to penetrate into the core of the artificially placed tumors as well as the immunologic consequences using an immunodeficient mouse model (i.e., failure to fully activate the ADCC response). Additional preclinical work determined that an anti-EGFR monoclonal antibody added to cisplatin therapy significantly enhanced xenograft growth inhibition [48]. Several investigators also found that the addition of an EGFR monoclonal antibody enhanced radiation sensitivity of head and neck cell lines in vitro, as well as in nude mouse xenografts $[18,49,50]$. The radiation response of A431 tumor xenografts was enhanced with EGFR monoclonal antibody therapy and this response was noted to be maintained with continued antibody treatment after radiation [51, 52]. More recently, Zhang et al. combined cetuximab and radiation therapy with the addition of cisplatin chemotherapy which resulted in the decreased survival of several human head and neck cancer cell lines [53].

In 1991, the first phase I trial of a mouse monoclonal antibody (IgG1) against EGFR was completed in advanced lung cancer patients and demonstrated antibody uptake at the tumor site [54]. Similarly, Perez-Soler et al., using an
IgG2 mouse monoclonal antibody, and Modjtahedi et al., using an IgG2 rat monoclonal antibody, targeted EGFR in patients with lung cancer and squamous cell carcinoma of the head and neck without significant toxicity $[55,56]$. The tolerability of the early mouse monoclonal antibody studies along with the positive results from the preclinical combinations of chimeric anti-EGFR antibodies with chemotherapy and radiotherapy lead to the development of single agent as well as combinational phase I studies with cetuximab in humans $[24,57,58]$. These studies demonstrated that patients were able to tolerate the combination of antiEGFR antibodies alone or in combination with either chemotherapy or radiation therapy. Only mild to moderate adverse events were noted with the most common adverse reaction being an acneiform rash.

\section{Cetuximab: Curative Treatment}

Nonsurgical curative treatment of locally advanced squamous cell carcinoma of the head and neck includes chemoradiation using concurrent platinum-based therapy as the most widely accepted standard of care. The benefit of adding cisplatin is often limited by toxicities or may not be feasible due to patient comorbidities such as diminished renal function, preexisting neuropathy, and poor auditory function. The clinical tolerability of cetuximab along with the preclinical data demonstrating benefit of adding cetuximab to radiation in vitro and in vivo led investigators to explore the use of cetuximab combined with radiation therapy in the curative setting (Table 2). Bonner et al. demonstrated in a phase III trial of 424 SCCHN patients randomized to radiation therapy alone or cetuximab and radiation therapy that the addition of cetuximab to radiation therapy increased the duration of locoregional control compared to radiation alone (24.4 months versus 14.9 , HR $0.68,95 \%$ CI $0.52-0.89, P=0.005)$ [18]. Overall survival at 3 years also favored the cetuximab cohort (55\% versus $45 \%, P=0.05)$. The cetuximab and radiation arm had higher rates of rashes/skin reactions and infusion reactions; otherwise, there was no difference in grade $3 / 4$ adverse events between treatment arms. This definitive study resulted in the FDA approving cetuximab for use in combination with radiation for the treatment of locally advanced squamous cell carcinoma of the head and neck in 2006. A follow-up report found that the overall $5 \mathrm{yr}$ survival was $45.6 \%$ versus $36.4 \%$ in the cetuximab and radiation arm versus the radiation alone arm, respectively 
TABLE 2: Cetuximab in the curative setting.

\begin{tabular}{|c|c|c|c|c|}
\hline Study & Year & Phase & Number of Patients/agent & Response (\%)/Survival (months) \\
\hline \multicolumn{5}{|c|}{ Cetuximab + radiation therapy } \\
\hline \multirow{3}{*}{ Bonner et al. $[18,19]$} & \multirow{3}{*}{$\begin{array}{l}2006 \\
2010\end{array}$} & \multirow{3}{*}{ III } & \multirow{3}{*}{$n=424$} & 3 yr PFS 42 versus $31^{*}$ \\
\hline & & & & 3 yr OS 55 versus $45^{*}$ \\
\hline & & & & 5 yr OS 45.6 versus $36.4^{*}$ \\
\hline \multicolumn{5}{|c|}{ Cetuximab + chemoradiation } \\
\hline \multirow{6}{*}{ Pfister et al. [20] } & \multirow{6}{*}{2006} & \multirow{6}{*}{ II } & \multirow{6}{*}{$n=22 ;$ cisplatin } & CR 13 \\
\hline & & & & PR 81 \\
\hline & & & & SD 0 \\
\hline & & & & DCR 94 \\
\hline & & & & 3 yr PFS 56 \\
\hline & & & & $3-y r$ OS 76 \\
\hline \multirow{4}{*}{ Langer et al. [21] (ECOG 3303) } & \multirow{4}{*}{2008} & \multirow{4}{*}{ II } & \multirow{4}{*}{$n=61 ;$ platinum therapy } & CR 23 \\
\hline & & & & PR 25 \\
\hline & & & & SD 31 \\
\hline & & & & DCR 79 \\
\hline \multirow{4}{*}{ Merlano et al. [22] } & \multirow{4}{*}{2011} & \multirow{4}{*}{ II } & \multirow{4}{*}{$n=45 ;$ cisplatin } & CR 71 \\
\hline & & & & PR 20 \\
\hline & & & & SD 0 \\
\hline & & & & DCR 94 \\
\hline \multirow{2}{*}{ Ang et al. [23] (RTOG 0522) } & \multirow{2}{*}{2011} & \multirow{2}{*}{ III } & \multirow{2}{*}{$n=895 ;$ cisplatin } & 2 yr PFS 63 versus 64 \\
\hline & & & & 2 yr OS 83 versus 80 \\
\hline
\end{tabular}

CR: complete response, PR: partial response, SD: stable disease, DCR: disease control rate (CR + PR + SD), PFS: progression-free survival, and OS: overall survival; * statistically significant.

[19]. Their data also suggested improved overall survival in patients experiencing at least a grade 2 acneiform rash during treatment.

With positive outcomes supporting the combination of cetuximab and radiation, investigators began to determine if cetuximab could be used in combination with standard platinum-based chemoradiation regimens. Pfister et al. undertook a phase II study of 22 patients with locally advanced SCCHN using weekly cetuximab with radiation combined with two high-dose cisplatin treatments [20]. Toxicities included mucositis, nausea/vomiting, dehydration, and abnormal renal function along with the known cetuximab-related grade 3/4 toxicities of acneiform rash $(10 \%)$ and infusion reactions (5\%). Due to high levels of toxicity, the trial was stopped early; however, longterm follow-up of the participants found a $3 \mathrm{yr}$ survival of $76 \%, 3 \mathrm{yr}$ progression-free survival rates of $56 \%$, and $3 \mathrm{yr}$ locoregional control rates of $71 \%$. Langer et al. reported using cisplatin (3 cycles) and weekly cetuximab concurrently with radiation therapy in 61 patients with locally advanced, unresectable SCCHN patients [21]. Objective responses were seen, but $97 \%$ of patients experienced a grade 3 or higher toxicity resulting in the observation that chemoradiation with cisplatin and cetuximab, while feasible, should be reserved for fit patients. An attempt to reduce toxicity was considered by Merlano et al. in a phase II study who used 3 cycles of low-dose cisplatin $\left(20 \mathrm{mg} / \mathrm{m}^{2}\right)$ given over
5 days with 5-FU in combination with weekly cetuximab and alternating weeks of daily XRT [22]. Median progressionfree survival of over 21 months and overall survival of 32.6 months was reported. With regard to toxicity, all 45 patients in the trial experienced mucositis (36\% grade 4 ) and radiodermatitis. Additionally, nearly $50 \%$ of patients required total parenteral nutrition support. Thus, toxicities are often the limiting factor in potentially beneficial regimens combining cetuximab with chemotherapy and radiation.

In 2011, results of the RTOG 0522 Phase III trial comparing cisplatin (given as 2 doses q 3 week) and radiation with and without weekly cetuximab in 895 locally advanced SCCHN patients were reported [23]. There was no difference in either progression-free survival (HR 1.05, 0.84-1.29; $P=$ 0.66 ) or overall survival (HR $0.87,0.66-1.15 ; P=0.17$ ) at two-year followup, despite increased toxicity, including mucositis and skin reactions in the cetuximab arm.

Questions remain if cetuximab combined with radiation is superior to cisplatin-based chemoradiotherapy. Caudell et al. retrospectively reviewed 31 patients treated with cetuximab and radiation and 103 patients with platinumbased chemotherapy and radiation and, after multivariate analysis, found no difference in $3 \mathrm{yr}$ locoregional control rates and $3 \mathrm{yr}$ overall survival between the treatment arms [59]. In contrast, a retrospective study from Koutcher et al. reviewed 174 locally advanced SCCHN patients treated with either cisplatin/XRT or cetuximab/XRT [60]. Results 
TABLE 3: Cetuximab in the palliative setting.

\begin{tabular}{|c|c|c|c|c|}
\hline Study & Year & Phase & Number of Patients/agent & Response (\%)/Survival (months) \\
\hline \multicolumn{5}{|c|}{ Cetuximab alone } \\
\hline \multirow[t]{3}{*}{ Baselga et al. [24] } & 2000 & I & $n=17$ & SD 69 \\
\hline & & & & CR 0 \\
\hline & & & & PR 13 \\
\hline \multirow[t]{3}{*}{ Vermorken et al. [25] } & 2007 & II & $n=103$ & SD 33 \\
\hline & & & & DCR 46 \\
\hline & & & & ORR 13 \\
\hline \multicolumn{5}{|c|}{ Cetuximab + chemotherapy } \\
\hline \multirow{5}{*}{ Baselga et al. [26] } & & & & CR 0 \\
\hline & & & & PR 10 \\
\hline & 2005 & II & $n=96 ;$ platinum therapy & SD 43 \\
\hline & & & & DCR 53 \\
\hline & & & & ORR 10 \\
\hline \multirow{5}{*}{ Herbst et al. [27] } & & & & CR 2 \\
\hline & & & & PR 12 \\
\hline & 2005 & II & $n=131 ;$ cisplatin/paclitaxel or cisplatin/5-FU & SD 50 \\
\hline & & & & DCR 64 \\
\hline & & & & ORR 13 \\
\hline \multirow{3}{*}{ Burtness et al. [28] } & & & & ORR 26 versus 10 \\
\hline & 2005 & III & $n=117 ;$ cisplatin & PFS 4.2 versus 2.7 \\
\hline & & & & OS 9.2 versus 8.0 \\
\hline \multirow{5}{*}{ Bourhis et al. [29] } & & & & CR 4 \\
\hline & & & & PR 32 \\
\hline & 2006 & $\mathrm{I} / \mathrm{II}$ & $n=53 ;$ platinum $/ 5-\mathrm{FU}$ & SD 38 \\
\hline & & & & DCR 74 \\
\hline & & & & ORR 36 \\
\hline \multirow{4}{*}{ Vermorken et al. [30] (EXTREME) } & \multirow{4}{*}{2008} & \multirow{4}{*}{ III } & \multirow{4}{*}{$n=442 ;$ platinum $/ 5-\mathrm{FU}$} & ORR 36 versus 20 \\
\hline & & & & DCR 81 versus 60 \\
\hline & & & & PFS 5.6 versus $3.3 \mathrm{mo}^{*}$ \\
\hline & & & & OS 10.1 versus $7.4 \mathrm{mo}^{*}$ \\
\hline
\end{tabular}

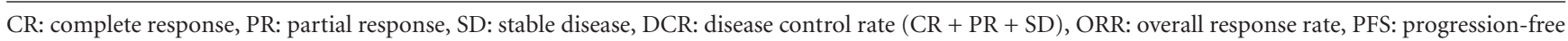
survival, and OS: overall survival; * statistically significant.

demonstrated $2 \mathrm{yr}$ overall survival of $66.6 \%$ versus $44.5 \%$, $2 \mathrm{yr}$ progression-free survival of $92.8 \%$ versus $87.4 \%$, and $2 \mathrm{yr}$ local control failure rates of $5.7 \%$ versus $39.9 \%$, in cisplatin/XRT combinations versus cetuximab/XRT combinations, respectively. Grade 3/4 toxicities were similar between treatment arms. Recently, Lefebvre et al. reported results from 153 patients with untreated, but surgically resectable, stage III/IV larynx or hypopharynx SCCHN who were randomized to treatment with either cisplatin + XRT or cetuximab + XRT following induction chemotherapy and found similar rates of laryngeal preservation $(86 \%$ versus $82 \%$ ) and survival ( $85 \%$ versus $86 \%$ ) between the treatments with the cisplatin + XRT treatment arm experiencing higher rates of late toxicity [61]. An on-going phase III trial (RTOG 1016; NCT01302834) is comparing radiation therapy with cisplatin versus cetuximab in locally advanced SCCHN with $5 \mathrm{yr}$ overall survival as the primary endpoint to determine which agent may be the most efficacious in patients with p16 positive oropharyngeal tumors.

\section{Cetuximab: Palliative Treatment}

Initial studies were designed to evaluate cetuximab in SCCHN patients with recurrent or metastatic disease (Table 3). In the trials discussed above, several patients demonstrated stable disease with cetuximab treatment alone [24]. Vermorken et al. conducted a phase II trial $(n=$ 103) in recurrent or metastatic stage III/IV SCCHN patients with progressive disease on platinum-based therapy where patients received weekly infusions of cetuximab alone until disease progression [25]. Analysis of the intent-to-treat population demonstrated a single agent disease control rate of $13 \%(\mathrm{CR}+\mathrm{PR}+\mathrm{SD})$ while a subgroup that received platinum-based therapy with cetuximab showed disease control rates of $46 \%$. Most common toxicities were grade 1 
or 2 acne-like skin reactions. One death from an infusionrelated reaction to cetuximab was reported.

In the palliative setting, two phase II trials demonstrated the benefit of combining cetuximab with platinum-based therapy in patients with recurrent or metastatic SCCHN who had progressed on prior treatment. Baselga et al. ( $n=$ 96) found an overall response rate of $10 \%$ using combined platinum-based therapy and cetuximab in a population with prior platinum exposure [26]. Disease control rates (CD + PR + SD) were $53 \%$ and a median survival of 183 days was reported in the intent-to-treat group. Sixty percent developed skin reactions, typically an acneiform rash, but less than $15 \%$ had a grade 3 or 4 skin reaction. Three of ninety-six patients had cetuximab-related infusion reactions. Herbst et al. enrolled 132 patients with stable or progressive disease after platinum-based therapy to a trial of cetuximab combined with cisplatin [27]. The stable disease group exhibited an objective response rate of $18 \%$ and a disease control rate of $76 \%$, while the progressive disease group (cohort 1) had rates of $20 \%$ and $64 \%$, respectively. A second group with progression on prior treatment, with a longer delay before starting the experimental arm, demonstrated objective response rates of $6 \%$ and disease control rates of $52 \%$. Infusion reactions were noted in approximately $13 \%$ of patients and the most common adverse event was an acne-like rash occurring in $70 \%$ of patients. In 2006, the FDA approved cetuximab as a single agent for the treatment of patients with recurrent or metastatic SCCHN for whom prior platinum-based therapy had failed.

A phase III trial designed for patients with recurrent or metastatic head and neck cancer without prior palliative treatment $(n=117)$ compared the use of cetuximab and cisplatin versus cisplatin alone [28]. The primary endpoint was progression-free survival; however, PFS was not significantly different between the treatment arms (4.2 months versus 2.7 months, $P=0.09$, HR $0.78,95 \%$ CI $0.54-1.12$ ). Similar results were found for overall survival $(9.2$ months versus 8.0 months, $P=0.21$ ); however, when survival was evaluated on the basis of time to develop skin toxicity, the estimated hazard ratio was 0.42 (95\% CI $0.21-0.86)$ and $P=0.01$. The objective response rate for the combinational therapy arm was $26 \%$ versus $10 \%$ in the cisplatin control group. Grade 3 and 4 toxicities were more frequent in the cetuximab and cisplatin cohort (90\% versus $73 \%)$. Skin rash occurred in $77 \%$ of the patients on the cetuximab and cisplatin arm versus $24 \%$ in the cisplatin alone group.

Further supportive evidence for the use of cetuximab with chemotherapy in the palliative setting was seen in a phase I/II trial $(n=53)$ of cetuximab combined with either carboplatin or cisplatin and 5-FU, which demonstrated an overall response rate of 36\% [29]. Adverse events were common, but only $15 \%$ of patients experienced a grade 3 or 4 adverse event. Acne-like rash was common in $56 \%$ of the treatment cohort.

These studies demonstrated that cetuximab could be used with cisplatin/5-FU treatments with modest, but tolerable, increases in adverse events and that the combination of cetuximab and cisplatin had improved response rates over chemotherapy alone. In 2008, Vermorken et al. investigated the use of cetuximab/platinum/5-FU versus platinum/5-FU as the first line treatment of patients with recurrent and metastatic SCCHN [30]. This phase III study evaluated 442 patients randomized to cetuximab + platinum-therapy/5FU versus chemotherapy alone with a primary endpoint of overall survival. Treatment could be with either cisplatin or carboplatin at the discretion of the treating physician. Patients received up to 6 cycles of chemotherapy and responding patients remained on cetuximab alone until progression. In the cetuximab group, overall survival was 10.1 months versus 7.4 months in the chemotherapy alone group (HR 0.80; 95\% CI 0.64-0.99; $P=0.04$ ). Progression free survival was 5.6 months in the cetuximab group versus 3.3 months in the chemotherapy alone group (HR 0.54; $95 \%$ CI $0.43-0.67, P<0.001$ ). The incidence of grade 3 and 4 adverse events was similar between study groups; however, the cetuximab group had more cases of sepsis, hypomagnesemia, skin reactions, and infusion reactions compared to the chemotherapy alone group. This study resulted in the FDA, in November 2011, approving cetuximab in combination with platinum-based therapy plus 5-FU for the first-line treatment of patients with recurrent locoregional disease and/or metastatic squamous cell carcinoma of the head and neck.

Also in the palliative setting, cetuximab has been shown to be active in combination with other chemotherapy agents. Hitt et al. investigated the use of cetuximab with weekly paclitaxel as a first-line treatment for recurrent and/or metastatic disease and found an overall response rate of 54\% and disease control rates (CR + PR + SD) of $80 \%$ with a median survival of 8.1 months [62]. Additionally, several small trials have demonstrated effective disease control using cetuximab in combination with taxanes and platinum-based therapy as first- and second-line interventions for recurrent and metastatic SCCHN [63-65]. Argiris et al. evaluated a combination of cetuximab with bevacizumab, an anti-VEGF monoclonal antibody, and noted partial response rates of $18 \%$ and stable disease $55 \%$ in heavily pretreated patients $(n=45)$. The median progression-free survival and overall survival were 2.8 and 7.6 months, respectively. Of note, the study generated 25 grade 4 adverse events and three grade 4 events [66]. Finally, a recent abstract found the combination of bendamustine and cetuximab in relapsed squamous cell carcinoma of the head and neck resulted in partial response rate of $36 \%$ and stable disease in $36 \%$ of patients $(n=28)$ who had failed prior therapy [67].

\section{Cetuximab Summary}

For treatment of SCCHN with curative intent, cetuximab combined with radiation therapy clearly has a benefit over radiation therapy alone. However, the addition of cetuximab to standard chemoradiation schemes using platinumbased therapy does not appear to enhance tumor response beyond that of standard chemoradiation, which remains the standard of care. As mentioned above, it is unknown if cetuximab is superior, equal to, or inferior to cisplatin-based chemoradiation, but this question will be pursued by future 
clinical trials. Questions also remain as to the benefit of cetuximab in combination with other chemotherapy agents and radiation as well as in other treatment regimens including induction chemotherapy and/or maintenance therapy. With respect to treatment of recurrent and/or metastatic SCCHN, the addition of cetuximab to platinum-based therapy and 5-FU improves patient survival and has recently been approved as first line therapy in the US. The above studies demonstrate clinical improvement with cetuximab, but there are also concerns for increased toxicity when combined with chemotherapy and/or radiation.

\section{Alternative Anti-EGFR Monoclonal Antibodies (Table 4)}

Panitumumab (Vectibix, formerly ABX-EGF) was the first fully humanized monoclonal IgG2 antibody developed against EGFR. Development of an IgG2 antibody resulted in an immunoglobulin species that is more resistant to enzyme degradation and consequently has a longer halflife $[68,69]$. Additionally, the humanized IgG2 antibody was also designed to be less immunogenic and to reduce the risk of hypersensitivity reactions; however, there is a question as to whether an IgG2 monoclonal antibody is effective in recruiting ADCC for an immunologically mediated anticancer effect [70].

The SPECTRUM trial was a phase III study to evaluate panitumumab in combination with chemotherapy versus chemotherapy alone as first line therapy for metastatic and/or recurrent squamous cell carcinoma of the head and neck [37]. The trial enrolled 657 patients with recurrent or metastatic squamous cell carcinoma of the head and neck who were randomized to platinum-based (cisplatin or carboplatin) chemotherapy +5 -FU or panitumumab in combination with platinum/5-FU therapy and measured overall survival as the primary endpoint. Cycles could be repeated up to six times and patients on the panitumumab arm had the option of receiving maintenance therapy until toxicity or disease progression. Median survival in the panitumumab arm was 11.1 months compared to 9.0 months in the chemotherapy alone arm; however, this difference was not statistically significant $(\mathrm{HR}=0.87,95 \% \mathrm{CI}: 0.73-$ 1.05; $P=0.14)$. The safety profile was similar between treatment arms. Initial subgroup analysis of performance status, age, sex, prior radiotherapy, region, or site of disease found no significant difference between the cohorts. However, when overall response was assessed by RECIST criteria, the panitumumab containing arm demonstrated higher rates of partial responses (35 versus 24\%) and better disease control $(\mathrm{CR}+\mathrm{PR}+\mathrm{SD} ; 84$ versus $72 \%, P=$ 0.004).

Further subgroup analysis of the SPECTRUM trial found that in an HPV-negative population subset, panitumumabtreated patients demonstrated overall survival benefit of 11.6 months versus 8.6 months (HR 0.73, $P=0.02$ ); however, this trend was not present in an HPV-positive subset (HR $0.96, P=0.88$ ) [71]. The potential benefit to HPV-negative populations is intriguing, but it should be noted that this analysis was performed retrospectively and samples were from the primary tumor and not the recurrences.

Additional trials have combined panitumumab with chemotherapy and radiation to augment tumor response. Wirth et al. investigated escalating doses of paclitaxel given with panitumumab, carboplatin, and radiation therapy for previously untreated, advanced stage SCCHN [35]. This regimen was associated with moderate toxicity; however, for all patients that completed therapy, an objective response of over $95 \%$ was demonstrated.

Zalutumumab (formerly HuMax-EGFr) is also a fully humanized anti-EGFR monoclonal antibody, an IgG1 isotype [72]. In a phase III trial $(n=286)$ with zalutumumab versus basic supportive care with optional methotrexate in platinum-refractory recurrent/metastatic SCCHN patients, Machiels et al. reported no significant difference in overall survival (6.7 months for zalutumumab arm and 5.2 months for control arm, HR 0.77 (97.06\% CI 0.57-1.05), $P=$ $0.065)$; however, progression-free survival was longer in the zalutumumab arm versus controls (9.9 weeks versus 8.4 weeks, HR 0.63 (95\% CI 0.47-0.84), $P=0.0012$ ). Overall the tumor response rate was $6.3 \%$ in the zalutumumab arm [38]. The safety profile was similar as the other anti-EFGR monoclonal antibodies with a grade $3-4$ rash occurring most frequently $(21 \%)$, although severe infusion-related reactions only occurred in $4 \%$ of patients.

Nimotuzumab (formerly h-R3 mAb) is a humanized antibody (approximately 10\% murine genes) with intermediate affinity to the EGF receptor. It was designed as an IgG1 isotype to enhance ADCC and potentiate tumor suppression, as well as to contain fewer foreign antigens to reduce infusionrelated reactions [73]. A phase I trial revealed the antibody was well tolerated with no serious adverse events and no acneiform rash was detected [74]. To evaluate nimotuzumab combined with radiation alone, Crombet et al. designed a phase I/II trial of 24 previously untreated, surgically unresectable, and locally advanced SCCHN patients [31]. Only mild to moderate adverse events were reported with the antibody in combination with radiation (mucositis, fever, hypotension, and tremors) and curiously, no skin rash was apparent. Disease control rates reported in the high-dose group were $87.5 \%$ with $\mathrm{CR}$ rates of $56 \%$. Additionally, it was noted that several of the patients experiencing a PR were able to become surgically resectable. Similarly, Rojo et al. designed a phase Ib trial with nimotuzumab in combination with radiation therapy in patients unable to receive chemotherapy due to poor nutritional status, cardiovascular comorbidities, or refusal to receive chemotherapy [32]. They determined that patients could tolerate nimotuzumab in combination with radiation and specifically did not experience the common acneiform rash typically associated with the inhibition of EGFR. The study was also undertaken to look for biomarkers of the EGFR/MAPK signaling pathway; nimotuzumab inhibited EGFR-phosphorylation, but had minimal effects on ERK1/2 and AKT phosphorylation. An additional randomized trial using combined nimotuzumab and radiation therapy in unresectable SCCHN patients demonstrated a median survival of 12.5 months versus 9.47 months for radiation therapy alone [33]. 
TABLE 4: Summary of alternative Anti-EGFR monoclonal antibodies.

\begin{tabular}{|c|c|c|c|c|c|}
\hline Study & Year & Phase & Agent & Number of Patients/agent & Response (\%)/Survival (months) \\
\hline \multicolumn{6}{|l|}{ Locally advanced } \\
\hline \multicolumn{6}{|c|}{ Antibody + radiation } \\
\hline \multirow{3}{*}{ Crombet et al. [31] } & & & & & CR 56 \\
\hline & 2004 & $\mathrm{I} / \mathrm{II}$ & Nimotuzumab & $n=16^{* *}$ & DCR 88 \\
\hline & & & & & 3 yr OS 67 \\
\hline \multirow{4}{*}{ Rojo et al. [32] } & \multirow{4}{*}{2010} & \multirow{4}{*}{ I } & \multirow{4}{*}{ Nimotuzumab } & \multirow{4}{*}{$n=10$} & CR 20 \\
\hline & & & & & PR 70 \\
\hline & & & & & SD 10 \\
\hline & & & & & DCR 90 \\
\hline \multirow[t]{2}{*}{ Rodríguez et al. [33] } & \multirow[t]{2}{*}{2010} & \multirow[t]{2}{*}{ II } & \multirow{2}{*}{ Nimotuzumab } & \multirow{2}{*}{$n=106$} & CR 60 \\
\hline & & & & & OS $12.5 \mathrm{mo}$ \\
\hline Babu et al. [34] & 2010 & II & Nimotuzumab & $n=36$ & 4 yr OS 34 \\
\hline \multicolumn{6}{|c|}{ Antibody + chemoradiation } \\
\hline \multirow{4}{*}{ Wirth et al. [35] } & \multirow{4}{*}{2010} & \multirow{4}{*}{ I } & \multirow{4}{*}{ Panitumumab } & \multirow{4}{*}{$n=19 ;$ paclitaxel/carboplatin } & CR 69 \\
\hline & & & & & PR 31 \\
\hline & & & & & SD 0 \\
\hline & & & & & DCR 100 \\
\hline \multirow{4}{*}{ Gupta and Madholia [36] } & \multirow{4}{*}{2010} & \multirow{4}{*}{ I } & \multirow{4}{*}{ Nimotuzumab } & \multirow{4}{*}{$n=17 ;$ weekly cisplatin } & CR 59 \\
\hline & & & & & PR 18 \\
\hline & & & & & SD 12 \\
\hline & & & & & DCR 89 \\
\hline Babu et al. [34] & 2010 & II & Nimotuzumab & $n=40 ;$ cisplatin & 4 yr OS 47 \\
\hline \multicolumn{6}{|l|}{ Palliative } \\
\hline \multirow{3}{*}{ Vermorken et al. [37] (SPECTRUM) } & \multirow{3}{*}{2010} & \multirow{3}{*}{ III } & \multirow{3}{*}{ Panitumumab } & & ORR 36 versus 25 \\
\hline & & & & $n=657 ;$ platinum therapy $/ 5-\mathrm{FU}$ & PFS 5.8 versus 4.6 \\
\hline & & & & & OS 11.1 versus 9.0 \\
\hline & & & & & DCR 48 versus 27 \\
\hline Machiels et al. [38] & 2011 & III & Zalutumumab & $n=286$; optional methotrexate & ORR 6.3 versus 1.1 \\
\hline & 2011 & 111 & Earutuntuminav & 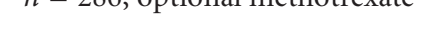 & PFS 2.5 versus 2.1 \\
\hline & & & & & OS 6.7 versus 5.2 \\
\hline & & & & & CR 6 \\
\hline Guo et al. [39] & 2011 & I & Nimotuzumab & $n=71 ;$ cisplatin/docetaxel/5-FU & PR 55 \\
\hline & & & & & SD 25 \\
\hline & & & & & DCR 86 \\
\hline
\end{tabular}

CR: complete response, PR: partial response, SD: stable disease, DCR: disease control rate (CR + PR + SD), ORR: overall response rate, PFS: progression-free survival, and OS: overall survival; ${ }^{*}$ statistically significant; ${ }^{* *}$ high-dose treatment group.

The benefit of nimotuzumab with radiation and chemotherapy was demonstrated by Gupta et al. who used weekly cisplatin with radiation and nimotuzumab in patients with locally advanced SCCHN [36]. The study found an objective response rate of $76 \%$ and no grade III or IV events were detected. However, without controlled data, it is difficult to ascertain the importance of this observation given the negative result of the RTOG 0522 trial. A phase IIb trial by Babu et al. evaluated inoperable SCCHN patients in treatment arms comparing nimotuzumab and chemoradiation $(\mathrm{N}+\mathrm{CRT})$ to chemoradiation (CRT) alone and nimotuzumab and radiation therapy $(\mathrm{N}+\mathrm{R})$ to radiation therapy alone (RT) [34]. Local regional control rates were higher in the arms combined with nimotuzumab. Four-year survival rates (using intent-to-treat analysis) demonstrated $47 \%$ in $\mathrm{N}+\mathrm{CRT}$ versus $21 \%$ in the CRT only arm $(P=$ 0.01 ) and $34 \%$ in $\mathrm{N}+\mathrm{RT}$ versus 13 in RT only arm (not significant). Also, a biomarker study was performed on this same patient group and it was found that EGFR expression by IHC correlated with patient survival, but phosphorylatedMAPK expression did not [75]. Thus, the survival benefits seen with nimotuzumab do not appear to correlate with 
the inhibition of the downstream signaling molecules of EGFR and suggest alternative mechanisms of enhanced tumor cell killing.

In the palliative setting, the combination of nimotuzumab with chemotherapy (cisplatin, docetaxel, and 5-FU) in 71 locally advanced head and neck patients who were not candidates for surgery or radiation therapy was reported by Guo et al. [39]. No serious adverse reactions were noted and overall response rate was $61 \%(\mathrm{CR}+\mathrm{PR})$.

Matuzumab (formerly EMD72000; Merck KGaA) is a humanized IgG1 monoclonal antibody targeting the EGFR receptor. An early phase I trial tested matuzumab in nine SCCHN patients and was found to have a favorable toxicity profile [76]. A second phase I trial with matuzumab confirmed a safe toxicity profile in a panel of solid tumor patients, including four head and neck patients [77]. However, no additional trials evaluating the efficacy of matuzumab alone or in combination with radiation and/or chemotherapy in SCCHN patients have been reported.

\section{Alternative Anti-EGFR Monoclonal Antibody Summary}

For palliative therapy for recurrent and/or metastatic SCCHN, the non-cetuximab monoclonal antibodies have not demonstrated significant benefit to date. However, limitations of panitumumab in the SPECTRUM trial may be as a result of the IgG2 isotype and failure to activate ADCC against the tumor. Zalutumumab also did not show a benefit, but the antibody containing treatment arm did not have a standard of care chemotherapy regimen. Nimotuzumab appears promising in combination with chemotherapy; its advantages are a humanized IgG1 which can activate ADCC but also reduces the risk of infusion reactions, treatment side effects including rash, and the development of human anti-mouse antibodies which could interfere with therapy. While these agents have demonstrated promise in Phase I and II studies, well-controlled, randomized phase III trials are necessary to demonstrate their efficacy against SCCHN.

\section{Future Directions}

The mechanism of action of EGFR targeting monoclonal antibodies is proposed to be a blockade of tumor survival signals that affect proliferation, apoptosis, and DNA repair as well as the stimulation of the immune system to recognize and target tumor cells for destruction. The specific isotype (IgG1 $\gg$ IgG2) of an antibody has a direct impact on its ability to activate ADCC [78]. Other antibody factors may also regulate ADCC activation. Posttranslational modifications, such as glycosylation, are important in stabilizing Fc receptor binding $[79,80]$. Patel et al. demonstrated that a glycosylated form of cetuximab had a greater than fourfold increase in ADCC-mediated cell lysis compared to an aglycosylated form of cetuximab in colon cancer cell lines [81]. Towards this end, Paz-Ares et al. presented results of a Phase I study ( $n=75)$ with a glycoengineered IgG1 antiEGFR monoclonal antibody (RO5083945; also known as
GA201/RG7160) and demonstrated moderate adverse events such as infusion reactions $(77 \%)$, rashes $(80 \% ; 25 \%$ grade 3 ) and hypomagnesemia (56\%). In a population of heavily pretreated metastatic solid tumor patients (including six head and neck patients), $4 \%$ had a complete or partial response, while $36 \%$ had stable disease [82]. Currently, RO5083945 is being tested in clinical trials as a single agent in head and neck cancer (NCT01046266) and in combination with chemotherapy in colon and nonsmall cell lung cancer (NCT01326000; NCT01185847).

Other modifications to EGFR monoclonal antibodies to enhance ADCC effects have also been proposed. Schlaeth et al. modified the $\mathrm{Fc}$ region of cetuximab to enhance NKcell recognition and found an enhanced cytotoxicity in KRas mutant lung carcinoma and colon cancer cell lines [83]. Another approach was the generation of a bispecific antibody (MDX-447) directed against EGFR and the high affinity Fc receptor to enhance ADCC $[84,85]$. A phase I trial demonstrated that MDX-447 was tolerated as a single agent in a population of metastatic solid tumors $(n=64,23 \%$ head and neck patients); however, a treatment arm in combination with growth factor support given to enhance ADCC was not tolerated [86]. Additionally, a recent in vitro study found that the double modification of Fc-glycosylation and Fc-protein recognition did not significantly enhance ADCC above the effects of each individual Fc modification [87].

Other manipulations of the immune system may prove useful to enhance the effectiveness of monoclonal antibodies. Research has demonstrated the upregulation of immune receptors, such as PD-1 (inhibitory) and CD137 (stimulatory), on NK cells, T-cells, and macrophages occurs when binding to the $\mathrm{Fc}$ domains of monoclonal antibodies [88-90]. Thus, targeting cetuximab-induced upregulation of T-cell expressed PD-1 or CD137 with an additional antibody could enhance the ADCC contribution to tumor cell kill. Recently, it was demonstrated that treatment with an antibody blocking the PD-1 receptor resulted in objective responses of nonsmall cell lung cancer, melanoma, and renal cell carcinoma [91].

Many preclinical and clinical studies have found added benefit in targeting multiple signaling pathways with combinations of antibodies and small molecule inhibitors, but often with higher rates of toxicity. Other investigators have specifically modified monoclonal antibodies in order to target multiple signaling pathways. An antibody targeting EGFR and the insulin growth factor receptor (IGF-R1) demonstrated antitumor effects against head and neck, colon, and pancreatic tumor cell lines as well as in mouse xenograft models [92]. Another group generated a dualtargeted antibody to VEGF and EGFR. Using head and neck, lung, and colon xenografts, they found suppressed tumor growth by the dual-targeted antibody, but interestingly, to a lesser extent than the combined treatment with individual cetuximab and bevacizumab antibodies [93, 94]. Similarly, other investigators generated a dual-targeted antibody, MEHD7945A, which targets EGFR and another growth factor receptor family member, Her3. Schaefer et al. established MEHN7945A inhibited EGFR, AKT, and ERK1/2 phosphorylation in vitro and caused growth inhibition in 
a NSCLC mouse xenograft model [95]. A phase I trial evaluating the safety of MEHN7945A in humans is underway (NCT01207323).

Alternative modifications of monoclonal antibodies have included conjugation to a radioactive isotope referred to as radioimmunotherapy (RIT). In several preclinical studies, investigators found efficacy and tolerability of anti-EGFR antibodies linked to In-111, I-131, and Bi-213 (an alphaemitting isotope) [96-98]. More recently, Liu et al. used radiolabeled Y-90 panitumumab to demonstrate a decreased proliferation of a head and neck cell line and improved survival of head and neck mouse xenografts [99]. While not in SCCHN, patients, a prior clinical trial used 188-Re labeled nimotuzumab in patients with glioblastoma multiforme and reported good tolerance to therapy [100].

One of the limitations of anti-EGFR antibody therapy is that currently, there are no biomarkers available to help clinicians predict which patients are most likely to benefit from treatment. Hitt et al. found that in recurrent/metastatic SCCHN the combination of weekly cetuximab and paclitaxel resulted in objective responses; however, no correlation between EGFR expression or copy number and overall survival was identified [62]. While it has been demonstrated that HPV-positive oropharyngeal tumors are associated with improved outcomes, it is unknown if anti-EGFR therapy is optimal for either HPV-positive or HPV-negative patients $[23,101]$. Thus, additional research is needed to find biomarkers that can be reflective of antibody response as well as prognostic of outcome.

In summary, cetuximab has clearly demonstrated an advantage in both the curative and palliative treatment settings for SCCHN. Related anti-EGFR antibodies, such as nimotuzumab, have also shown efficacy, as well as a more tolerable side effect profile. Additional preclinical studies and future prospective clinical trials are necessary to find specific subsets of patients who will optimally benefit from treatment with anti-EGFR monoclonal antibodies.

\section{References}

[1] ACS, Cancer Facts and Figures 2012, American Cancer Society, Atlanta, Ga, USA, 2012.

[2] J. Ferlay, H. R. Shin, F. Bray, D. Forman, C. Mathers, and D. M. Parkin, "Estimates of worldwide burden of cancer in 2008: GLOBOCAN 2008," International Journal of Cancer, vol. 127, no. 12, pp. 2893-2917, 2010.

[3] B. E. Brockstein, "Management of recurrent head and neck cancer: recent progress and future directions," Drugs, vol. 71, no. 12, pp. 1551-1559, 2011.

[4] R. J. Koness, A. Glicksman, L. Liu et al., "Recurrence patterns with concurrent platinum-based chemotherapy and accelerated hyperfractionated radiotherapy in stage III and IV head and neck cancer patients," American Journal of Surgery, vol. 174, no. 5, pp. 532-535, 1997.

[5] B. Brockstein, D. J. Haraf, A. W. Rademaker et al., "Patterns of failure, prognostic factors and survival in locoregionally advanced head and neck cancer treated with concomitant chemoradiotherapy: a 9-year, 337-patient, multiinstitutional experience," Annals of Oncology, vol. 15, no. 8, pp. 1179-1186, 2004.
[6] O. Dassonville, J. L. Formento, M. Francoual et al., "Expression of epidermal growth factor receptor and survival in upper aerodigestive tract cancer," Journal of Clinical Oncology, vol. 11, no. 10, pp. 1873-1878, 1993.

[7] K. K. Ang, B. A. Berkey, X. Tu et al., "Impact of epidermal growth factor receptor expression on survival and pattern of relapse in patients with advanced head and neck carcinoma," Cancer Research, vol. 62, no. 24, pp. 7350-7356, 2002.

[8] C. H. Chung, J. S. Parker, G. Karaca et al., "Molecular classification of head and neck squamous cell carcinomas using patterns of gene expression," Cancer Cell, vol. 5, no. 5, pp. 489-500, 2004.

[9] S. M. Bentzen, B. M. Atasoy, F. M. Daley et al., "Epidermal growth factor receptor expression in pretreatment biopsies from head and neck squamous cell carcinoma as a predictive factor for a benefit from accelerated radiation therapy in a randomized controlled trial," Journal of Clinical Oncology, vol. 23, no. 24, pp. 5560-5567, 2005.

[10] C. H. Chung, K. Ely, L. McGavran et al., "Increased epidermal growth factor receptor gene copy number is associated with poor prognosis in head and neck squamous cell carcinomas," Journal of Clinical Oncology, vol. 24, no. 25, pp. 4170-4176, 2006.

[11] L. Licitra, R. Mesia, F. Rivera et al., "Evaluation of EGFR gene copy number as a predictive biomarker for the efficacy of cetuximab in combination with chemotherapy in the firstline treatment of recurrent and/or metastatic squamous cell carcinoma of the head and neck: EXTREME study," Annals of Oncology, vol. 22, no. 5, pp. 1078-1087, 2011.

[12] J. Mendelsohn and J. Baselga, "The EGF receptor family as targets for cancer therapy," Oncogene, vol. 19, no. 56, pp. 6550-6565, 2000.

[13] C. L. Arteaga, "The epidermal growth factor receptor: from mutant oncogene in nonhuman cancers to therapeutic target in human neoplasia," Journal of Clinical Oncology, vol. 19, supplement 18, pp. 32S-40S, 2001.

[14] F. Ciardiello and G. Tortora, "A novel approach in the treatment of cancer: targeting the epidermal growth factor receptor," Clinical Cancer Research, vol. 7, no. 10, pp. 29582970, 2001.

[15] J. A. McCubrey, L. S. Steelman, W. H. Chappell et al., "Roles of the Raf/MEK/ERK pathway in cell growth, malignant transformation and drug resistance," Biochimica et Biophysica Acta, vol. 1773, no. 8, pp. 1263-1284, 2007.

[16] P. J. Roberts and C. J. Der, "Targeting the Raf-MEK-ERK mitogen-activated protein kinase cascade for the treatment of cancer," Oncogene, vol. 26, no. 22, pp. 3291-3310, 2007.

[17] B. H. Jiang and L. Z. Liu, "PI3K/PTEN signaling in tumorigenesis and angiogenesis," Biochimica et Biophysica Acta, vol. 1784, no. 1, pp. 150-158, 2008.

[18] J. A. Bonner, P. M. Harari, J. Giralt et al., "Radiotherapy plus cetuximab for squamous-cell carcinoma of the head and neck," The New England Journal of Medicine, vol. 354, no. 6, pp. 567-578, 2006.

[19] J. A. Bonner, P. M. Harari, J. Giralt et al., "Radiotherapy plus cetuximab for locoregionally advanced head and neck cancer: 5-year survival data from a phase 3 randomised trial, and relation between cetuximab-induced rash and survival," The Lancet Oncology, vol. 11, no. 1, pp. 21-28, 2010.

[20] D. G. Pfister, Y. B. Su, D. H. Kraus et al., "Concurrent cetuximab, cisplatin, and concomitant boost radiotherapy for locoregionally advanced, squamous cell head and neck cancer: a pilot phase II study of a new combined-modality 
paradigm," Journal of Clinical Oncology, vol. 24, no. 7, pp. 1072-1078, 2006.

[21] C. J. Langer, J. W. Lee, U. A. Patel et al., "Preliminary analysis of ECOG, 3303: Concurrent radiation (RT), cisplatin (DDP) and cetuximab (C) in unresectable, locally advanced (LA) squamous cell carcinoma of the head and neck (SCCHN)," Journal of Clinical Oncology, vol. 26, supplement 20, abstract 6006, 2008.

[22] M. Merlano, E. Russi, M. Benasso et al., "Cisplatin-based chemoradiation plus cetuximab in locally advanced head and neck cancer: a phase II clinical study," Annals of Oncology, vol. 22, no. 3, pp. 712-717, 2011.

[23] K. K. Ang, Q. E. Zhang, D. I. Rosenthal et al., "A randomized phase III trial (RTOG, 0522) of concurrent accelerated radiation plus cisplatin with or without cetuximab for stage III-IV head and neck squamous cell carcinomas (HNC)," Journal of Clinical Oncology, vol. 29, abstract 5500, 2011.

[24] J. Baselga, D. Pfister, M. R. Cooper et al., "Phase I studies of anti-epidermal growth factor receptor chimeric antibody C225 alone and in combination with cisplatin," Journal of Clinical Oncology, vol. 18, no. 4, pp. 904-914, 2000.

[25] J. B. Vermorken, J. Trigo, R. Hitt et al., "Open-label, uncontrolled, multicenter phase II study to evaluate the efficacy and toxicity of cetuximab as a single agent in patients with recurrent and/or metastatic squamous cell carcinoma of the head and neck who failed to respond to platinumbased therapy," Journal of Clinical Oncology, vol. 25, no. 16, pp. 2171-2177, 2007.

[26] J. Baselga, J. M. Trigo, J. Bourhis et al., "Phase II multicenter study of the antiepidermal growth factor receptor monoclonal antibody cetuximab in combination with platinumbased chemotherapy in patients with platinum-refractory metastatic and/or recurrent squamous cell carcinoma of the head and neck," Journal of Clinical Oncology, vol. 23, no. 24, pp. 5568-5577, 2005.

[27] R. S. Herbst, M. Arquette, D. M. Shin et al., "Phase II multicenter study of the epidermal growth factor receptor antibody cetuximab and cisplatin for recurrent and refractory squamous cell carcinoma of the head and neck," Journal of Clinical Oncology, vol. 23, no. 24, pp. 5578-5587, 2005.

[28] B. Burtness, M. A. Goldwasser, W. Flood, B. Mattar, and A. A. Forastiere, "Phase III randomized trial of cisplatin plus placebo compared with cisplatin plus cetuximab in metastatic/recurrent head and neck cancer: An Eastern Cooperative Oncology Group Study," Journal of Clinical Oncology, vol. 23, no. 34, pp. 8646-8654, 2005.

[29] J. Bourhis, F. Rivera, R. Mesia et al., "Phase I/II study of cetuximab in combination with cisplatin or carboplatin and fluorouracil in patients with recurrent or metastatic squamous cell carcinoma of the head and neck," Journal of Clinical Oncology, vol. 24, no. 18, pp. 2866-2872, 2006.

[30] J. B. Vermorken, R. Mesia, F. Rivera et al., "Platinum-based chemotherapy plus cetuximab in head and neck cancer," The New England Journal of Medicine, vol. 359, no. 11, pp. 11161127, 2008.

[31] T. Crombet, M. Osorio, T. Cruz et al., "Use of the humanized anti-epidermal growth factor receptor monoclonal antibody h-R3 in combination with radiotherapy in the treatment of locally advanced head and neck cancer patients," Journal of Clinical Oncology, vol. 22, no. 9, pp. 1646-1654, 2004.

[32] F. Rojo, E. Gracias, N. Villena et al., "Pharmacodynamic trial of nimotuzumab in unresectable squamous cell carcinoma of the head and neck: A SENDO Foundation study," Clinical Cancer Research, vol. 16, no. 8, pp. 2474-2482, 2010.
[33] M. O. Rodríguez, T. C. Rivero, R. D. C. Bahi et al., "Nimotuzumab plus radiotherapy for unresectable squamous-cell carcinoma of the head and neck," Cancer Biology and Therapy, vol. 9, no. 5, pp. 343-349, 2010.

[34] K. G. Babu, L. Viswanath, B. K. Reddy et al., "An open-label, randomized, study of h-R3mAb (nimotuzumab) in patients with advanced (stage III or IVa) squamous cell carcinoma of head and neck (SCCHN): four-year survival results from a phase IIb study," Journal of Clinical Oncology, vol. 28, abstract 5530, p. 15s, 2010.

[35] L. J. Wirth, A. M. Allen, M. R. Posner et al., "Phase I dose-finding study of paclitaxel with panitumumab, carboplatin and intensity-modulated radiotherapy in patients with locally advanced squamous cell cancer of the head and neck," Annals of Oncology, vol. 21, no. 2, pp. 342-347, 2010.

[36] M. Gupta and V. Madholia, "Results from a pilot study of nimotuzumab with concurrent chemoradiation in patients with locally advanced squamous cell carcinoma of the head and neck," vol. 28, no. 15s, abstract 5565, 2010.

[37] J. B. Vermorken, J. Stohlmacher, F. Cognetti et al., "Primary Efficacy and Safety Results of SPECTRUM, a Phase III Trial in Patients With Recurrent and/or Metastatic Squamous Cell Carcinoma of the Head and Neck (R/M-SCCHN) Receiving Chemotherapy With or Without Panitumumab," in Proceedings of the 35th ESMO Congress, Milan, Italy, October 2010.

[38] J. P. Machiels, S. Subramanian, A. Ruzsa et al., "Zalutumumab plus best supportive care versus best supportive care alone in patients with recurrent or metastatic squamous-cell carcinoma of the head and neck after failure of platinumbased chemotherapy: An open-label, randomised phase 3 trial," The Lancet Oncology, vol. 12, no. 4, pp. 333-343, 2011.

[39] W. Guo, G. Ren, C. Li et al., "Pilot study of target therapy with EGFR antibody (nimotuzumab) in patients with unresectable head and neck cancer," Journal of Clinical Oncology, vol. 29, abstract e16008, 2011.

[40] N. I. Goldstein, M. Prewett, K. Zuklys, P. Rockwell, and J. Mendelsohn, "Biological efficacy of a chimeric antibody to the epidermal growth factor receptor in a human tumor xenograft model," Clinical Cancer Research, vol. 1, no. 11, pp. 1311-1318, 1995.

[41] J. D. Sato, T. Kawamoto, A. D. Le, J. Mendelsohn, J. Polikoff, and G. H. Sato, "Biological effects in vitro of monoclonal antibodies to human epidermal growth factor receptors," Molecular Biology \& Medicine, vol. 1, no. 5, pp. 511-529, 1983.

[42] G. N. Gill, T. Kawamoto, and C. Cochet, "Monoclonal anti-epidermal growth factor receptor antibodies which are inhibitors of epidermal growth factor binding and antagonists of epidermal growth factor-stimulated tyrosine protein kinase activity," Journal of Biological Chemistry, vol. 259, no. 12, pp. 7755-7760, 1984.

[43] Z. Fan, Y. Lu, X. Wu, and J. Mendelsohn, "Antibody-induced epidermal growth factor receptor dimerization mediates inhibition of autocrine proliferation of A431 squamous carcinoma cells," Journal of Biological Chemistry, vol. 269, no. 44, pp. 27595-27602, 1994.

[44] M. Naramura, S. D. Gillies, J. Mendelsohn, R. A. Reisfeld, and B. M. Mueller, "Therapeutic potential of chimeric and murine anti-(epidermal growth factor receptor) antibodies in a metastasis model for human melanoma," Cancer Immunology Immunotherapy, vol. 37, no. 5, pp. 343-349, 1993. 
[45] H. Kimura, K. Sakai, T. Arao, T. Shimoyama, T. Tamura, and K. Nishio, "Antibody-dependent cellular cytotoxicity of cetuximab against tumor cells with wild-type or mutant epidermal growth factor receptor," Cancer Science, vol. 98, no. 8, pp. 1275-1280, 2007.

[46] J. Kurai, H. Chikumi, K. Hashimoto et al., "Antibodydependent cellular cytotoxicity mediated by cetuximab against lung cancer cell lines," Clinical Cancer Research, vol. 13, no. 5, pp. 1552-1561, 2007.

[47] H. Masui, T. Kawamoto, and J. D. Sato, "Growth inhibition of human tumor cells in athymic mice by anti-epidermal growth factor receptor monoclonal antibodies," Cancer Research, vol. 44, no. 3, pp. 1002-1007, 1984.

[48] Z. Fan, J. Baselga, H. Masui, and J. Mendelsohn, "Antitumor effect of anti-epidermal growth factor receptor monoclonal antibodies plus cis-diamminedichloroplatinum on well established A431 cell xenografts," Cancer Research, vol. 53, no. 18, pp. 4637-4642, 1993.

[49] S. M. Huang, J. M. Bock, and P. M. Harari, "Epidermal growth factor receptor blockade with C225 modulates proliferation, apoptosis, and radiosensitivity in squamous cell carcinomas of the head and neck," Cancer Research, vol. 59, no. 8, pp. 1935-1940, 1999.

[50] S. M. Huang and P. M. Harari, "Modulation of radiation response after epidermal growth factor receptor blockade in squamous cell carcinomas: inhibition of damage repair, cell cycle kinetics, and tumor angiogenesis," Clinical Cancer Research, vol. 6, no. 6, pp. 2166-2174, 2000.

[51] L. Milas, K. Mason, N. Hunter et al., "In vivo enhancement of tumor radioresponse by C225 antiepidermal growth factor receptor antibody," Clinical Cancer Research, vol. 6, no. 2, pp. 701-708, 2000.

[52] L. Milas, F. M. Fang, K. A. Mason et al., "Importance of maintenance therapy in C225-induced enhancement of tumor control by fractionated radiation," International Journal of Radiation Oncology Biology Physics, vol. 67, no. 2, pp. 568$572,2007$.

[53] N. Zhang, K. Erjala, J. Kulmala et al., "Concurrent cetuximab, cisplatin, and radiation for squamous cell carcinoma of the head and neck in vitro," Radiotherapy and Oncology, vol. 92, no. 3, pp. 388-392, 2009.

[54] C. R. Divgi, S. Welt, M. Kris et al., "Phase I and imaging trial of indium 111-labeled anti-epidermal growth factor receptor monoclonal antibody 225 in patients with squamous cell lung carcinoma," Journal of the National Cancer Institute, vol. 83, no. 2, pp. 97-104, 1991.

[55] R. Perez-Soler, N. J. Donato, D. M. Shin et al., "Tumor epidermal growth factor receptor studies in patients with non- small-cell lung cancer or head and neck cancer treated with monoclonal antibody RG 83852," Journal of Clinical Oncology, vol. 12, no. 4, pp. 730-739, 1994.

[56] H. Modjtahedi, T. Hickish, M. Nicolson et al., "Phase I trial and tumour localisation of the anti-EGFR monoclonal antibody ICR62 in head and neck or lung cancer," British Journal of Cancer, vol. 73, no. 2, pp. 228-235, 1996.

[57] F. Robert, M. P. Ezekiel, S. A. Spencer et al., "Phase I study of anti-epidermal growth factor receptor antibody cetuximab in combination with radiation therapy in patients with advanced head and neck cancer," Journal of Clinical Oncology, vol. 19, no. 13, pp. 3234-3243, 2001.

[58] D. M. Shin, N. J. Donato, R. Perez-Soler et al., "Epidermal growth factor receptor-targeted therapy with C225 and cisplatin in patients with head and neck cancer," Clinical Cancer Research, vol. 7, no. 5, pp. 1204-1213, 2001.
[59] J. J. Caudell, S. M. Sawrie, S. A. Spencer et al., "Locoregionally advanced head and neck cancer treated with primary radiotherapy: a comparison of the addition of cetuximab or chemotherapy and the impact of protocol treatment," International Journal of Radiation Oncology Biology Physics, vol. 71, no. 3, pp. 676-681, 2008.

[60] L. Koutcher, E. Sherman, and M. Fury, "Concurrent cisplatin and radiation versus cetuximab and radiation for locally advanced head-and-neck cancer," International Journal of Radiation Oncology, Biology and Physics, vol. 81, no. 4, pp. 915-922, 2011.

[61] J. Lefebvre, Y. Pointreau, F. Rolland et al., "Sequential chemoradiotherapy (SCRT) for larynx preservation (LP): results of the randomized phase II TREMPLIN study," Journal of Clinical Oncology, vol. 29, supplement, abstract 5501, 2011.

[62] R. Hitt, A. Irigoyen, H. Cortes-Funes et al., "Phase II study of the combination of cetuximab and weekly paclitaxel in the first-line treatment of patients with recurrent and/or metastatic squamous cell carcinoma of head and neck," Annals of Oncology, vol. 23, no. 4, pp. 1016-1022, 2011.

[63] J. Buentzel, A. de Vries, and O. Micke, "Experience with Cetuximab plus paclitaxel/carboplatinum in primary platinum-resistant recurrent head and neck cancer," Journal of Clinical Oncology, vol. 25, no. 18s, 2007, ASCO Annual Meetings Proceedings Part I.

[64] M. K. Knoedler, T. Gauler, A. Matzdorff et al., "Multicenter phase II study of cetuximab plus docetaxel in 84 patients with recurrent or metastatic, platinum-pretreated SCCHN," Journal of Clinical Oncology, vol. 27, abstract 6048, p. 15s, 2009.

[65] J. Guigay, J. Fayette, A. Dillies et al., "Cetuximab, Docetaxel, and cisplatin (TPEx) as first-line treatment in patients with recurrent or metastatic (R/M) squamous cell carcinoma of the head and neck (SCCHN): first results of phase II trial GORTEC, 2008-03," Journal of Clinical Oncology, vol. 29, abstract 5567, 2011.

[66] A. Argiris, A. P. Kotsakis, S. Kim et al., "Phase II trial of Cetuximab (C) and Bevacizumab (B) in recurrent or metastatic squamous cell carcinoma of the head and neck (SCCHN): final results," Journal of Clinical Oncology, vol. 29, abstract 5564, 2011.

[67] B. Tschechne, I. Wildfang, H. Niebuhr et al., "Bendamustine and Cetuximab as an alternative therapeutic option for recurrent head and neck squamous cell carcinoma," Journal of Clinical Oncology, vol. 28, supplement, abstract e16029, 2010.

[68] I. R. Correia, "Stability of IgG isotypes in serum," MAbs, vol. 2, no. 3, pp. 221-232, 2010.

[69] B. B. Yang, P. Lum, A. Chen et al., "Pharmacokinetic and pharmacodynamic perspectives on the clinical drug development of panitumumab," Clinical Pharmacokinetics, vol. 49, no. 11, pp. 729-740, 2010.

[70] T. Schneider-Merck, J. J. Van Lammerts Bueren, S. Berger et al., "Human IgG2 antibodies against epidermal growth factor receptor effectively trigger antibody-dependent cellular cytotoxicity but, in contrast to IgG1, only by cells of myeloid lineage," Journal of Immunology, vol. 184, no. 1, pp. 512-520, 2010.

[71] J. Stoehlmacher-Williams, C. Villanueva, P. Foa et al., "Safety and efficacy of panitumumab in HPV positive and HPV negative recurrent/metastatic SCC of HN: analysis of the phase III SPECTRUM trial," in Proceedings of the European Multidisciplinary Cancer Congress, 2011. 
[72] M. B. Overdijk, S. Verploegen, J. H. van den Brakel et al., "Epidermal growth factor receptor (EGFR) antibodyinduced antibody-dependent cellular cytotoxicity plays a prominent role in inhibiting tumorigenesis, even of tumor cells insensitive to EGFR signaling inhibition," The Journal of Immunology, vol. 187, no. 6, pp. 3383-3390, 2011.

[73] C. Mateo, E. Moreno, K. Amour, J. Lombardero, W. Harris, and R. Pérez, "Humanization of a mouse monoclonal antibody that blocks the epidermal growth factor receptor: recovery of antagonistic activity," Immunotechnology, vol. 3, no. 1, pp. 71-81, 1997.

[74] T. Crombet, L. Torres, E. Neninger et al., "Pharmacological evaluation of humanized anti-epidermal growth factor receptor, monoclonal antibody h-R3, in patients with advanced epithelial-derived cancer," Journal of Immunother$a p y$, vol. 26, no. 2, pp. 139-148, 2003.

[75] C. Basavaraj, P. Sierra, J. Shivu, R. Melarkode, E. Montero, and P. Nair, "Nimotuzumab with chemoradiation confers survival advantage in treatment naïve head and neck tumors overexpressing EGFR," Cancer Biology and Therapy, vol. 10, no. 7, pp. 673-681, 2010.

[76] H. Bier, T. Hoffmann, U. Hauser et al., "Clinical trial with escalating doses of the antiepidermal growth factor receptor humanized monoclonal antibody EMD 72000 in patients with advanced squamous cell carcinoma of the larynx and hypopharynx," Cancer Chemotherapy and Pharmacology, vol. 47, no. 6, pp. 519-524, 2001.

[77] U. Vanhoefer, M. Tewes, F. Rojo et al., "Phase I study of the humanized antiepidermal growth factor receptor monoclonal antibody EMD72000 in patients with advanced solid tumors that express the epidermal growth factor receptor," Journal of Clinical Oncology, vol. 22, no. 1, pp. 175-184, 2004.

[78] R. Clynes, "Antitumor antibodies in the treatment of cancer: Fc receptors link opsonic antibody with cellular immunity," Hematology/Oncology Clinics of North America, vol. 20, no. 3, pp. 585-612, 2006.

[79] S. Krapp, Y. Mimura, R. Jefferis, R. Huber, and P. Sondermann, "Structural analysis of human IgG-Fc glycoforms reveals a correlation between glycosylation and structural integrity," Journal of Molecular Biology, vol. 325, no. 5, pp. 979-989, 2003.

[80] R. Jefferis, "Glycosylation as a strategy to improve antibodybased therapeutics," Nature Reviews Drug Discovery, vol. 8, no. 3, pp. 226-234, 2009.

[81] D. Patel, X. Guo, S. Ng et al., "IgG isotype, glycosylation, and EGFR expression determine the induction of antibodydependent cellular cytotoxicity in vitro by cetuximab," Human Antibodies, vol. 19, no. 4, pp. 89-99, 2010.

[82] L. G. Paz-Ares, C. Gomez-Roca, J. P. Delord et al., "Phase I pharmacokinetic and pharmacodynamic dose-escalation study of RG7160 (GA201), the first glycoengineered monoclonal antibody against the epidermal growth factor receptor, in patients with advanced solid tumors," Journal of Clinical Oncology, vol. 29, no. 28, pp. 3783-3790, 2011.

[83] M. Schlaeth, S. Berger, S. Derer et al., "Fc-engineered EGF$\mathrm{R}$ antibodies mediate improved antibody-dependent cellular cytotoxicity (ADCC) against KRAS-mutated tumor cells," Cancer Science, vol. 101, no. 5, pp. 1080-1088, 2010.

[84] R. T. Curnow, "Clinical experience with CD64-directed immunotherapy. An overview," Cancer Immunology Immunotherapy, vol. 45, no. 3-4, pp. 210-215, 1997.

[85] A. B. Van Spriel, H. H. Van Ojik, and J. G. J. Van de Winkel, "Immunotherapeutic perspective for bispecific antibodies," Immunology Today, vol. 21, no. 8, pp. 391-397, 2000.
[86] M. G. Fury, A. Lipton, K. M. Smith, C. B. Winston, and D. G. Pfister, "A phase-I trial of the epidermal growth factor receptor directed bispecific antibody MDX-447 without and with recombinant human granulocyte-colony stimulating factor in patients with advanced solid tumors," Cancer Immunology, Immunotherapy, vol. 57, no. 2, pp. 155-163, 2008.

[87] R. Repp, C. Kellner, A. Muskulus et al., "Combined Fcprotein- and $\mathrm{Fc}$-glyco-engineering of scFv-Fc fusion proteins synergistically enhances CD16a binding but does not further enhance NK-cell mediated ADCC," Journal of Immunological Methods, vol. 373, pp. 167-278, 2011.

[88] P. A. Ascierto, E. Simeone, M. Sznol, Y. X. Fu, and I. Melero, "Clinical experiences with anti-CD137 and anti-PD1 therapeutic antibodies," Seminars in Oncology, vol. 37, no. 5, pp. 508-516, 2010.

[89] J. Pander, M. Heusinkveld, T. van der Straaten et al., "Activation of tumor-promoting type 2 macrophages by EGFRtargeting antibody cetuximab," Clinical Cancer Research, vol. 17, no. 17, pp. 5668-5673, 2011.

[90] J. Stagg, S. Loi, U. Divisekera et al., "Anti-ErbB-2 mAb therapy requires type I and II interferons and synergizes with anti-PD-1 or anti-CD137 mAb therapy," Proceedings of the National Academy of Sciences of the United States of America, vol. 108, no. 17, pp. 7142-7147, 2011.

[91] S. L. Topalian, F. S. Hodi, J. R. Brahmer et al., "Safety, activity, and immune correlates of anti-PD-1 antibody in cancer," The New England Journal of Medicine, vol. 366, no. 26, pp. 24432454, 2012.

[92] J. Dong, A. Sereno, D. Aivazian et al., "A stable IgG-Like bispecific antibody targeting the epidermal growth factor receptor and the type I insulin-like growth factor receptor demonstrates superior anti-tumor activity," MAbs, vol. 3, no. 3, pp. 273-288, 2011.

[93] H. Zhang, S. Yun, and T. D. Batuwangala, "A dual-targeting antibody against EGFR-VEGF for lung and head and neck cancer treatment," International Journal of Cancer, vol. 131, no. 4, pp. 956-969, 2012.

[94] S. J. Hurwitz, H. Zhang, S. Yun et al., "Pharmacodynamics of DT-IgG, a dual-targeting antibody against VEGF-EGFR, in tumor xenografted mice," Cancer Chemotherapy and Pharmacology, vol. 69, no. 3, pp. 577-590, 2012.

[95] G. Schaefer, L. Haber, L. M. Crocker et al., "A two-in-one antibody against HER3 and EGFR has superior inhibitory activity compared with monospecific antibodies," Cancer Cell, vol. 20, no. 4, pp. 472-486, 2011.

[96] M. J. Mattes and D. M. Goldenberg, "Therapy of human carcinoma xenografts with antibodies to EGFr and HER-2 conjugated to radionuclides emitting low-energy electrons," European Journal of Nuclear Medicine and Molecular Imaging, vol. 35, no. 7, pp. 1249-1258, 2008.

[97] B. Pfost, C. Seidl, M. Autenrieth et al., "Intravesical $\alpha$ radioimmunotherapy with $213 \mathrm{Bi}$-anti-EGFR-mAb defeats human bladder carcinoma in xenografted nude mice," Journal of Nuclear Medicine, vol. 50, no. 10, pp. 1700-1708, 2009.

[98] D. Rades, C. Wolff, R. Nadrowitz et al., "Radioactive EGFR antibody cetuximab in multimodal cancer treatment: stability and synergistic effects with radiotherapy," International Journal of Radiation Oncology Biology Physics, vol. 75, no. 4, pp. 1226-1231, 2009.

[99] Z. Liu, Y. Liu, B. Jia et al., "Epidermal growth factor receptortargeted radioimmunotherapy of human head and neck cancer xenografts using90Y-labeled fully human antibody 
panitumumab," Molecular Cancer Therapeutics, vol. 9, no. 8, pp. 2297-2308, 2010.

[100] A. Casaco, G. López, R. Fernandez et al., "Loco-regional radioimmunotherapy of high grade malignant gliomas using the humanized monoclonal antibody, h-R3, labeled with 188-Re," Journal of Clinical Oncology, vol. 22, no. 14S, abstract 2530, 2004, ASCO Annual Meeting Proceedings (Post-Meeting Edition).

[101] S. R. Schwartz, B. Yueh, J. K. McDougall, J. R. Daling, and S. M. Schwartz, "Human papillomavirus infection and survival in oral squamous cell cancer: a population-based study," Otolaryngology, vol. 125, no. 1, pp. 1-9, 2001. 


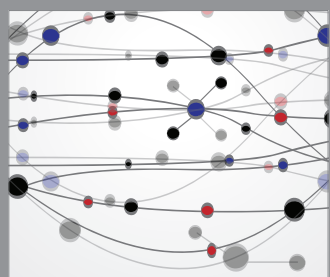

The Scientific World Journal
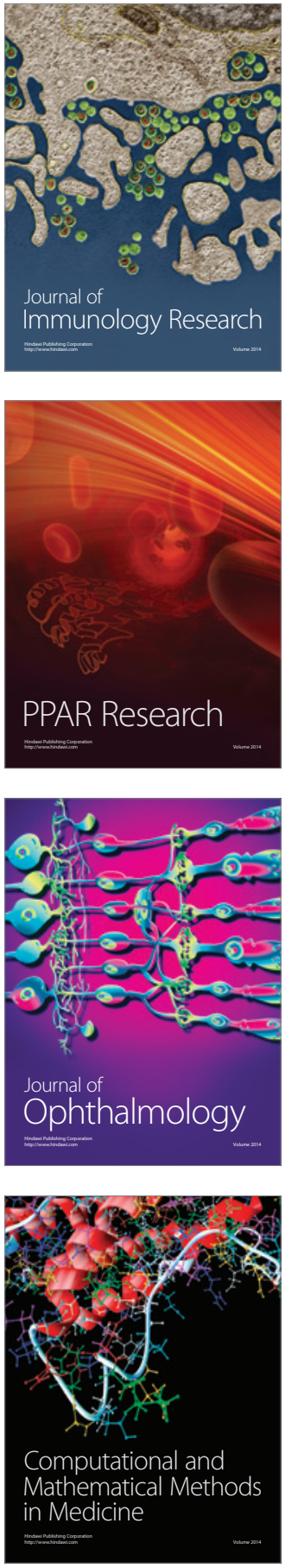

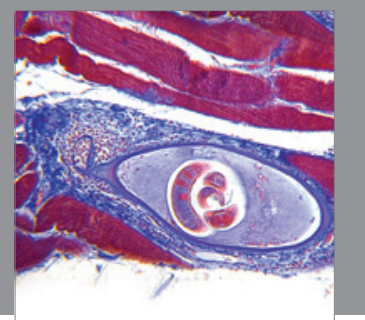

Gastroenterology

Research and Practice
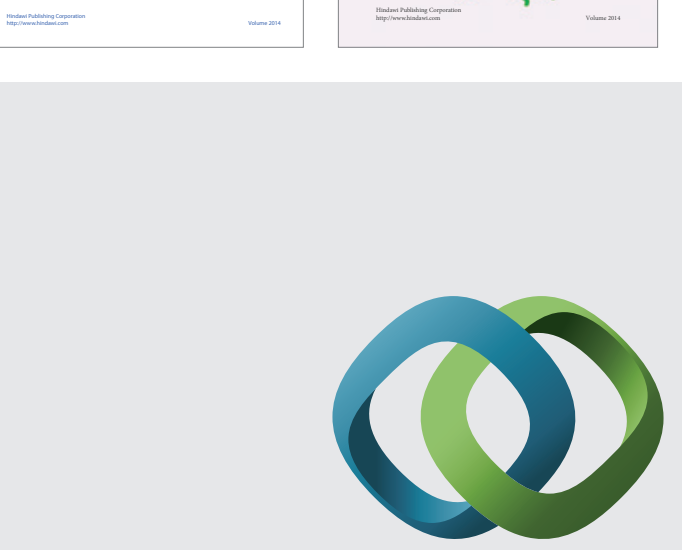

\section{Hindawi}

Submit your manuscripts at

http://www.hindawi.com
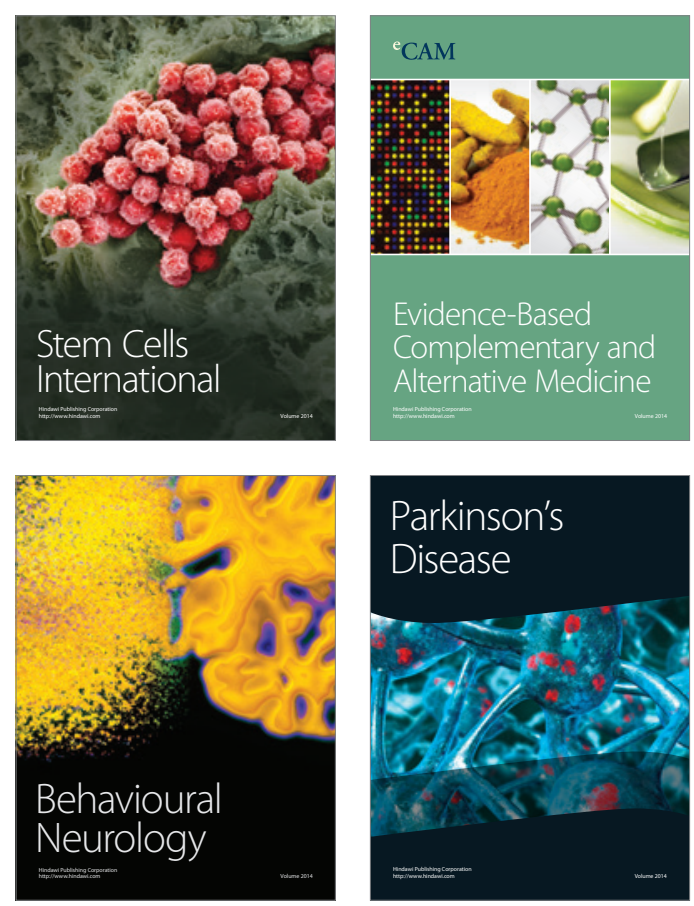

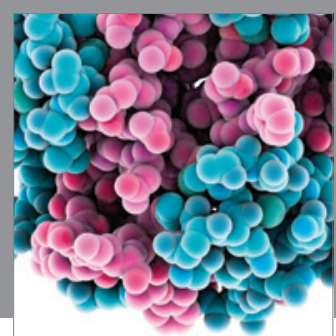

Journal of
Diabetes Research

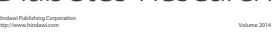

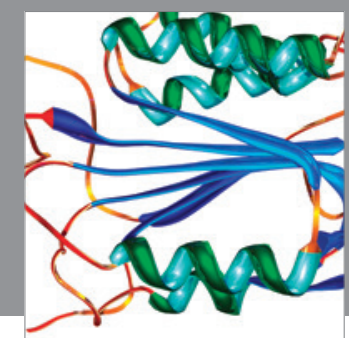

Disease Markers
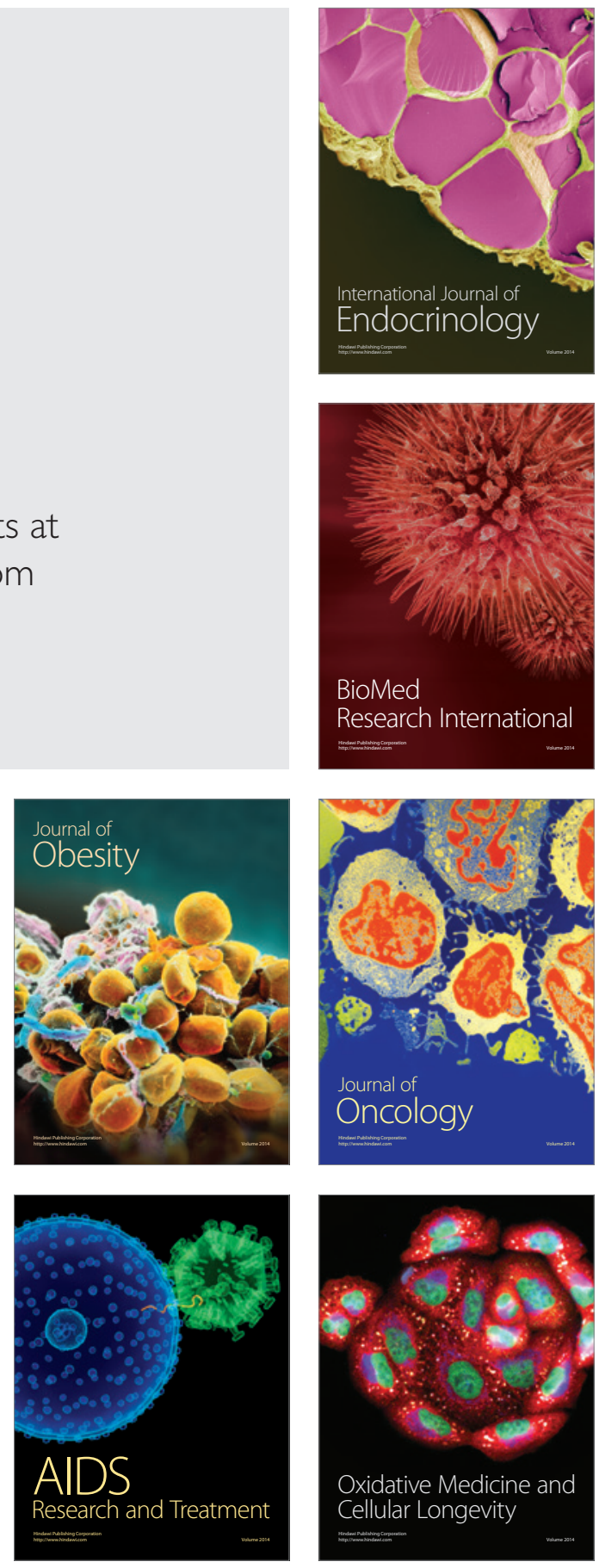